\title{
The Argentinian Crystal Growing Contest and other educational activities in Argentina during the COVID-19 pandemic
}

\author{
S. Klinke ${ }^{1,2}$, V.C. Fuertes ${ }^{1,3}$, V.G. Franco ${ }^{1,4}$, C.E. Álvarez ${ }^{1,5}$, D.G. Lamas ${ }^{1,6}$ \\ ${ }^{1}$ Argentinian Association of Crystallography (AACr) \\ ${ }^{2}$ Fundación Instituto Leloir, IIBBA-CONICET, Ciudad Autónoma de Buenos Aires, Argentina \\ ${ }^{3}$ INFIQC, UNC-CONICET, Facultad de Ciencias Químicas, Córdoba Capital, Pcia. de Córdoba, Argentina \\ ${ }^{4}$ Instituto de Física del Litoral, UNL-CONICET, Santa Fe Capital, Pcia. de Santa Fe, Argentina \\ ${ }^{5}$ Centro de Estudios Fotosintéticos y Bioquímicos-CONICET, FBioyF-UNR, Rosario, Pcia. de Santa Fe, Argentina \\ ${ }^{6}$ ITECA, UNSAM-CONICET, ECyT, Laboratorio de Cristalografia Aplicada, San Martín, Pcia. de Buenos Aires, Argentina
}

E-mail:dlamas@unsam.edu.ar

The celebration of the International Year of Crystallography (IYCr2014) in Argentina was an unforgettable experience, with a lot of academic, educational and dissemination activities all over the country including exhibitions, science fairs, art or photo contests, and outreach talks, among other events. Many members of the Argentinian Association of Crystallography (AACr) participated enthusiastically and, in this way, it was possible to bring Crystallography to all provinces in our country. The most important activity launched by the AACr for the IYCr2014 was the "National Crystal Growing Contest for High Schools", which also involved the organization of 38 short courses on Crystallography and Crystal Growth for training of primary and secondary school teachers all over the country. The students, organized in teams of a maximum of three or individually, had to perform a crystal growing project, guided by their teachers, and submit a short video or written essay presenting their results and conclusions. The contest was a complete success, receiving about 500 projects of high scientific quality and creativity. Through this exciting, funny and hands-on scientific experience, Crystallography and other related scientific fields were promoted along the Argentinian high school community, being also a way to encourage young students to continue exploring Science and developing their scientific skills.

Considering the great success of the first edition, the AACr decided to continue this activity annually in the frame of the "Legacy of the IYCr2014" initiative. The Contest continued to arouse great enthusiasm, with the participation of hundreds of schools and training more than one thousand teachers every year. It is worth to mention that many of them also participated in the "IUCr Crystal Growing Competition for Schoolchildren", the international contest organized by the IUCr, with great success. As such, Argentina has been the country with the highest number of projects submitted in every edition.

The COVID-19 pandemic has represented a global challenge since March 2020 and many congresses, courses and outreach activities could not take place or had to be postponed. However, as 2020 progressed, some of these difficulties were overcome. Many virtual courses were organized and some of them, thanks to the online modality, reached new regions or countries. Therefore, the AACr decided to continue with the Contest, this time proposing students to work from home with simple and inexpensive materials, without any danger. In addition, bibliographic research works related to Crystallography were also accepted in the 2020 edition, allowing the participation of students that could not grow crystals at home or school but that were interested in joining our activity. Many students accepted the challenge and 90 works were received. Many of them involved the growth of single or polycrystals, but others were interesting research projects related to the history of Crystallography and some of the great milestones of our science field. The short courses on Crystallography and Crystal Growth, taught in a new virtual format, were very successful too, receiving a large number of new participants not only from Argentinian cities not visited by AACr members in the previous years, but also from all over Latin America. In this way, 15 online short courses were organized, with the participation of over 4,000 teachers. The year finished with a virtual awards ceremony, opened to the general public, in which the finalists selected by the jury had the opportunity to share their experience.

In conclusion, even though 2020 has been a very difficult year, the AACr has continued with the dissemination of Crystallography, and similar activities are nowadays in progress in the frame of the 2021 edition of the National Crystal Growing Contest.

\section{Keywords: Teaching of Crystallography; Crystal Growing; Education}

We are grateful to the following institutions for supporting in the National Crystal Growing Contest: IUCr, Argentinian Research Council (CONICET) through its VocAr Initiative (Programa de Promoción de Vocaciones Científicas), Balseiro Foundation, and Argentinian Ministry of Science, Technology and Innovation. Special thanks to the AACr members, regional representatives and local Education Ministries that help us organize this federal activity. 